\title{
ABORDAGEM SOBRE OS ASPECTOS DO MEIO FÍSICO DA TERRA INDÍGENA URU-EU-WAU-WAU
}

\author{
ENFOQUE SOBRE LOS ASPECTOS DEL MEDIO FÍSICO DE TIERRAS \\ INDÍGENAS URU-EU-WAU-WAU
}

\author{
APPROACH ON THE ASPECTS OF THE PHYSICAL \\ ENVIRONMENT OF INDIGENOUS LAND URU-EU-WAU-WAU
}

\begin{abstract}
Adnilson de Almeida Silva
Especialista em Análise Ambiental da Amazônia e Mestre em Geografia pela Universidade Federal de Rondônia - UNIR. Doutorando em Geografia pela Universidade Federal do Paraná (UFPR). Pesquisador-colaborador do Núcleo de Estudos em Espaços e Representações - NEER e do Grupo de Estudos e Pesquisas sobre Modos de Vida e Populações Amazônicas - GEP Cultura Amazônica/UNIR. Bolsista da CAPES. E-mail: adnilsonn@hotmail.com
\end{abstract}

\author{
Alexis de Souza Bastos \\ Graduado em Geografia e Mestre em Geografia pela UNIR. Coordenador de Projetos do Centro \\ de Estudos da Cultura e do Meio Ambiente da Amazônia - RIOTERRA \\ Av. Norte-sul, 7300 - Bairro Nova Morada. CEP: 78987-000 \\ E-mail: alexisbastos@ hotmail.com
}

\begin{abstract}
Resumo
O presente artigo abordará os aspectos físicos gerais da Terra Indígena Uru-Eu-WauWau, como geomorfologia, geologia e hidrologia, estabelecendo as relações de sua importância socioambiental no contexto regional. A abordagem pretendida ocorre com o estabelecimento interdisciplinar, através de processos morfogenéticos e pedogenéticos que permitem compreender pelo menos em parte, a complexidade ambiental e a identificação das vulnerabilidades permitindo ao homem intervir e encontrar alternativas para conservar e preservar as matérias naturais contidas naquele espaço.

Palavras-Chave: Geomorfologia. Meio ambiente. Terra Indígena Uru-Eu-Wau-Wau. Vulnerabilidades.
\end{abstract}

\section{Resumen}

Este artículo presenta los aspectos físicos generales de la Tierras indígena Uru-Eu-WauWau, como geomorfología, geología y hidrología, haciendo establecendo las relaciones de su importancia ambiental y sociale en el contexto regional. El enfoque se produce com el establecimento interdisciplinario, a través de procesos morfogenéticos y pedogenéticos que permiten entender por lo menos en parte, la complejidad ambiental y la identificación de las vulnerabilidades permitiendo al hombre intervenir y buscar 
alternativas para conservar y preservar las materiales naturales contenidos en ese espacio.

Palabras-Clave: Geomorfología. Medio Ambiente. Tierras indígenas Uru-Eu-WauWau. Vulnerabilidades.

\begin{abstract}
The present article will approach the aspects physical general of the Terra Indígena Uru$\mathrm{Eu}-\mathrm{Wau}-\mathrm{Wau}$, specially as for the geomorphology, geology and hydrology, establishing the relations of its ambient partner importance in the regional context. The intended boarding occurs with the establishment to interdisciplinary, through morphogenetics and pedogenetics processes that allow to understand at least in part, the ambient complexity and the identification of the vulnerabilities allowing to the man to intervened and to find alternatives to conserve and to preserve the contained natural substances in that space.

Key-words: Geomorphology. Environment. Terra Indígena Uru-Eu-Wau-Wau. Vulnerabilities.
\end{abstract}

\title{
Introdução
}

A abordagem sobre as questões que envolvem aspectos do meio físico da Terra Indígena Uru-Eu-Wau-Wau - TIUEWW é complexa e há uma carência de literatura que trata especificamente dessa porção geográfica.

Os poucos estudos existentes, como RADAMBRASIL realizado na década de 1970-1980, trata de uma macro-abordagem regional, ou seja, em uma escala de análise muito grande, o mesmo acontecendo com o Diagnóstico Etnoambiental Participativo da Terra Indígena Uru-Eu-Wau-Wau (2002) que enfatizou as questões com base no RADAMBRASIL. No caso do presente artigo será feito um pequeno resumo a partir desses trabalhos mencionados, através de uma análise geral.

Recentemente o IBGE dispôs em seu banco de dados, através de mapas temáticos, questões de meio físico envolvendo a Bacia do rio Jamari, inserida na TIUEWW, porém sem oferecer uma descrição pormenorizada das feições geomorfológicas, geológicas e de vegetação, ou seja, continuando com o mesmo problema de escala, e que não será objeto na presente análise. 


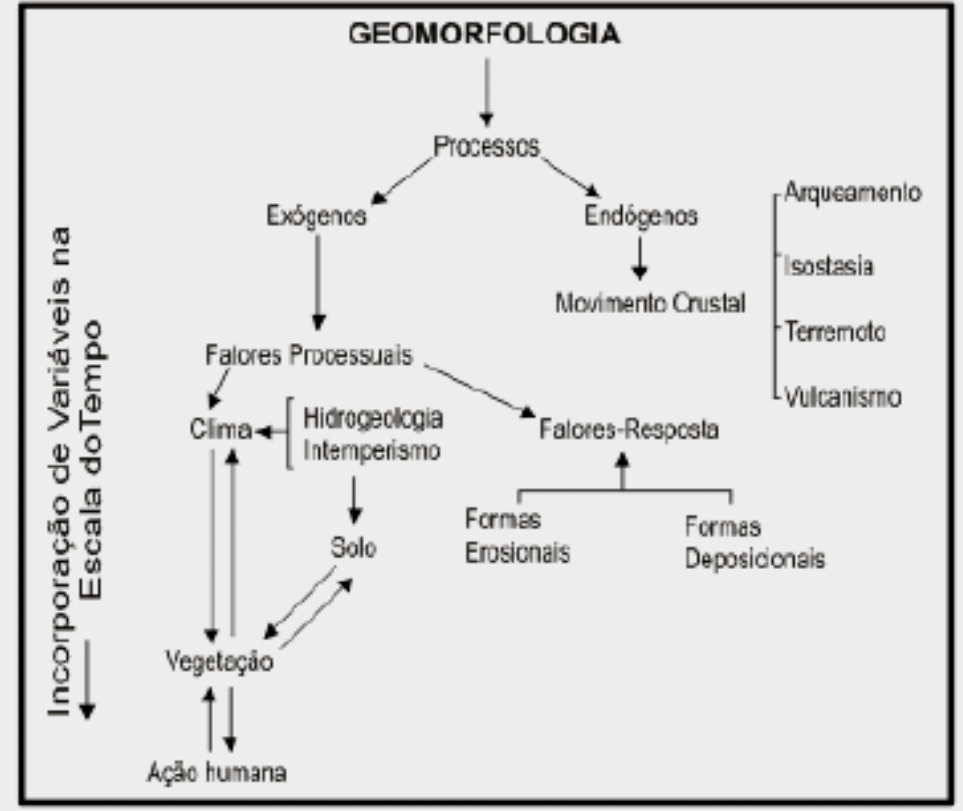

Fig. 1 - Dinâmica processual em Geomorfologia (adaptado de King apud Casseti, 2001)

O presente artigo com base nessas informações se propõe em entender algumas dessas questões, inferindo a interdisciplinaridade para entender a complexidade ambiental da região proposta, através da metodologia desenvolvida por Valter Casseti (2001, p. 05), representada na Figura 1.

As recentes transformações políticas, sociais, econômicas e ambientais, as quais Rondônia vem experimentando nos últimos quarenta anos, como resultado da política de colonização e ocupação da Amazônia, permite a análise, conforme assegura Casseti (1995, p. 19-20):

[...] as relações de produção (relação homem-homem), ao mesmo tempo em que implicam as relações entre o homem e a natureza (forças produtivas), respondem pelo comportamento da superestrutura [...] em sua unidade dialética com as relações de produção, constituem a base material do modo de produção que caracteriza cada época histórica [...] quanto maior o avanço científico-tecnológico de um povo, menores serão as imposições do meio natural e maiores as transformações acontecidas, o que implica o próprio comportamento ambiental.

Desse modo, o estudo compreende que o significado do relevo tem que ser visto como um geossistema, entendido de forma associada, estabelecendo relações processuais como um todo, ou seja, é de sua interdependência a explicação para os fenômenos que se processam na superfície terrestre em decorrências dos fatores endógenos e exógenos.

Ateliê Geográfico Goiânia-GO $\quad$ v. 5,n.1 mar/2011 $\quad$ p.85-102 Página 87


Para melhor entender esses fatores, é necessário entender o objetivo da ciência geomorfológica, cuja proposição Casseti, 1995, conceituou como o de "explicar as transformações do geo-relevo, portanto, não apenas quanto à morfologia (forma) como também à fisiologia (função), incorporado organicamente ao movimento histórico das sociedades"

A apropriação do relevo e suas transformações, com a utilização de um recurso, nas palavras de Becht e Belzung apud Claude Raffestin (1993, p. 225) "é o produto de uma relação. A partir daí, não há recursos naturais, só matérias naturais”. Assim, sem ocorrer uma relação ou intervenção externa verifica-se que a matéria é e permanece como sempre foi.

\section{Considerações sobre a geomorfologia Tiueww}

O relevo é entendimento como o resultado dos processos e ações desencadeadas ao longo do tempo geológico, podendo ser reconstituída e recomposto através das evidências fortemente ligadas a formas antigas ou paleoformas, como os depósitos correlativos ou formas específicas decorrentes dos mecanismos morfogenéticos.

Ao abordar sobre a evolução do relevo, Casseti $^{2}$, entende que ela é resultado da incorporação do antagonismo determinado pelas forças endógenas, comandadas pelas atividades tectônicas, e exógenas, relativas aos processos morfoclimáticos. $\mathrm{Na}$ análise sobre o relevo atual, os fatores internos são postos num segundo plano, pois suas representações são resultados de uma escala de tempo geológico, ocorrendo, todavia, exceções como às manifestadas catastroficamente como no caso dos processos de vulcanismos, tectonismos ou abalos sísmicos, que configuram as áreas de dobramentos recentes.

A geomorfogênese como resultado dessas forças antagônicas, propicia a evolução e o desenvolvimento de formas semelhantes em seus tipos de modelados. As formas, por sua vez, estão em subordinação à intensidade e frequiência das ações processuais em que ocorrem as reações tectônico-estruturais, capazes de produzir marcas, que podem ser destruídas ou preservadas.

\footnotetext{
${ }^{1}$ op cit. p. 36

2 op. cit 5-6 (2001)
} 
A TIUEWW localiza-se inserida na unidade estrutural denominada de área cratônica do pré-Cambriano superior na Plataforma Amazônica, conforme Petri e Fúlfaro (1983) apud Casseti (2001), ou seja, em região estabilizada geotectonicamente, representada por escudos antigos, situados entre 1.000-1.300 MA. A morfologia exprime em virtude dessa idade, o retrabalhamento das rochas pré-existentes, com uma configuração especial marcada por eventos morfoclimáticos.

Para entendimento do resultado da combinação de diferentes componentes da natureza, o relevo é uma importante fonte de materiais para a delimitação das paisagens, condicionando a forma de uso e ocupação do solo. Neste contexto Casseti ${ }^{3}$ entende que o significado do relevo na delimitação da paisagem pode ser justificado da seguinte forma:

[...] Relações de forças contrárias: o relevo, decorrente do jogo de forças internas e externas, leva à interpenetração de formas. Assim sendo, considerando as escalas temporais e espaciais, ora o relevo pode expressar mais as influências estruturais, ora os efeitos morfoclimáticos, ou ainda ambos, simultaneamente. [...] O relevo acaba se constituindo no resultado dessas forças contrárias, razão pela qual se reveste de importância enquanto subsídio para a demarcação de diferenças morfológicas, com diferenças pedológicas e conseqüentemente relativas ao uso e ocupação do solo, numa perspectiva "possibilista"; [...] Relações morfopedológicas: muitos trabalhos têm demonstrado estreita relação entre a disposição do relevo e os solos resultantes, o que tem cada vez mais consolidado a morfopedologia [...] encontra-se, via de regra, determinada pelo balanço entre morfogênese e pedogênese, pois, enquanto em áreas tabulares prevalece a componente perpendicular (infiltração), nas fortemente dissecadas predomina a paralela (escoamento), numa estreita relação de tendência crescente com a declividade. Tais parâmetros oferecem sustentação ao processo de apropriação do relevo, insistindo na perspectiva possibilista; [...] Relações antropomorfológicas: o processo de apropriação do relevo seja como suporte ou como recurso, vincula-se ao comportamento da morfologia e às condições pedológicas. [...] Tal relação não se dá de forma determinística, partindo do princípio de que a disponibilidade tecnológica, aliada à força do capital, seja capaz de superar eventuais obstáculos morfológicos.

No caso da TIUEWW essas relações de alteração do modelado terrestre têm se transcorrido com pouca intensidade, uma vez que ela encontra-se com baixo nível de antropização, exceto em locais que sofreram invasão e em litígio dominial como o Projeto de Assentamento Dirigido Burareiro. A caracterização das relações morfopedológicas e antropomorfológicas nesses locais tem provocado grandes

\footnotetext{
${ }^{3}$ op. cit 3-4 (2001)
} 
alterações tanto no modelado quanto na rede de drenagem hidrográfica, em consequiência do desflorestamento de morros e vertentes, acentuando os processos erosivos.

Em relação à geologia da TIUEWW, conforme os dados do Atlas Geoambiental de Rondônia (2002, p-38 48), têm como terrenos tecno-estratigráficos os Domínios Central de Rondônia (CRD) e Terreno Nova Brasilândia, e como formações verifica-se a Palheiral e Nova Floresta (Neoproterozóico); Suíte Intrusiva Alto Candeias; Suíte Granítica Rio Pardo; Formação Migrantinópolis pertencente ao Grupo Nova Brasilândia (Mesoproterozóico); Complexo Jamari (Paleoproterozóico) e Cobertura Cenozóica. Essas formações, em sua maioria, foram compostas por falhas ou zonas de cisalhamento.

O Terreno Nova Brasilândia teve seus preenchimentos caracterizados por seqüências de ciclos alternados envolvendo glaciação e desertificação.

A morfologia e a topografia da TIEWW apresentam-se feições geomorfológicas bem distintas, representadas pelo embasamento cristalino de idade que vai do Paleoproterozóico, permeando o Mesoproterozóico, o Neoproterozóico, o Paleozóico, o Mesozóico; e finalmente, sedimentos inconsolidados de cobertura de idade Cenozóica.

Pelas informações do Atlas Geoambiental de Rondônia (2002, p-50-55) a compartimentação regional da TIEWW tem 03 grandes ambientes geomorfológicos: áreas de domínio de superfícies regionais de aplanamento de Nível II; serras constituídas por rochas sedimentares antigas na forma de superfícies tabulares; cuestas e "hogbacks", conforme pode ser visto no Anexo I.

As informações do RADAMBRASIL (1978) apud Kanindé (2002) afirmam que a TIUEWW é composta por agrupamentos de morros e colinas; unidades denudacionais, serras e as montanhas, situando-se no domínio dos Planaltos Residuais do Guaporé, tendo a sudeste e nordeste o Planalto Dissecado Sul da Amazônia, localizando-se entre a Depressão Interplanáltica da Amazônia Meridional e o Pediplano Centro Ocidental Brasileiro.

\section{Planalto residual do Guaporé}

O Planalto Residual do Guaporé é compreendido pelos planaltos tabulares em terrenos cristalinos aplainados, como as Serras dos Parecis com arenitos do Cretáceo,

Ateliê Geográfico Goiânia-GO v. 5,n.1 mar/2011 p.85-102 Página 90


Uopianes e Pacaás Novos do Proterozóico Superior. Essas estruturas são marcadas com processos erosivos marcantes em seus desníveis altimétricos.

Dentro dessa estrutura, a serra dos Pacaás Novos é a mais imponente possuindo cotas altimétricas superiores a $700 \mathrm{~m}$, destacando-se o Pico do Tracoá, com mais de $1000 \mathrm{~m}$ de altitude.

A TIUEWW é o berço das nascentes dos principais rios que contribuem para a Bacia do Madeira e Amazonas, como é o caso do Jamari - onde está a única hidrelétrica do Estado - Cautário, São Miguel, Urupá, Pacaás Novos, sendo, portanto vitais por ser estarem em uma área praticamente sem antropização, exceto nas regiões de invasão e de litígio.

A natureza dos sedimentos é do tipo coluvionar oriundos da Serra dos Pacaás Novos, verificando-se nela os morros tabulares, mesetas e "canyons", ali se encontram rochas basálticas e sedimentos Terciários-Quaternários fluviais, localmente lateritizados. Existem nessa região planícies sedimentares.

Em Uopianes, o relevo é tabular, composto por arenitos pré-cambrianos da formação Palmeiral. Com a reativação tectônica ocorreu o soerguimento dos blocos e o basculamento no jurocretácico, com movimentos tectônicos rigorosos, cujos efeitos são encontrados em várias áreas da Amazônia, de acordo com o Radambrasil (1978).

$\mathrm{Na}$ Serra do Uopianes, os relevos tabulares se posicionam na direção geral nordeste sudoeste e se dividem em 2 conjuntos de blocos que se estendem à margem direita e esquerda do Rio Cautário. As bordas muito dissecadas e sobre os topos tabulares encontram-se relevos residuais (com aspecto ruiniforme), denominados de inselbergs. A Serra do Uopianes apresenta os mesmos tipos de solos e de cobertura vegetal identificado na Serra dos Pacaás Novos, com afloramentos rochosos nos topos dos relevos elevados, enquanto nas partes rebaixadas destacam-se solos litólicos.

\section{Pediplano Centro-Ocidental Brasileiro}

É uma superfície aplainada rebaixado topograficamente, situada na parte centroocidental do Brasil. O pediplano isolou um conjunto de relevos dos Planaltos residuais do Guaporé, constituído pela Serra do Uopianes e Pacaás Novos, com pedimentos detríticos. 
A Unidade recebe, localmente, o nome de Comandante Ary, com relevos dissecados em interflúvios tabulares onde ocorre uma faixa solos rasos compostos por sedimentos arenosos e com cobertura vegetal de Savana e campos, ocorrendo à presença de grandes lajedos, inselbergs, formação de cavernas com desenhos rupestres nestas mesetas ou inselbergs. Ocorrem ainda as lagoas isoladas.

\section{Planalto Dissecado Sul Da Amazônia}

Compreende a parte centro-oriental do Estado, tendo como rede de drenagem composta pelos rios Candeias, Jamari e Machado. É um relevo fragmentado e pontilhado por intrusões graníticas do Pré-Cambriano, determinando as formas de morros de topo convexo, com cristas com altitudes atingindo 400 metros, contornadas e interpenetradas por uma superfície mais baixa. O trecho cortado pelos rios Candeias e Jamari apresentam relevo bastante dissecado.

\section{Evolução paleoclimática e equilíbrio geomorfológico}

A Evolução Paleoclimática e Instalação de Drenagem na TIUEWW é identificada pelas superfícies pediplanadas, caracterizando uma sucessão de episódios climáticos diferenciados, de acordo com Radambrasil (1978).

A presença de fácies arenosas, estruturas truncadas e ocorrência de relevos residuais no topo da serra dos Pacaás Novos e do Uopianes são resultantes de uma superfície elaborada que sofreu "processos mecânicos" com a pediplanação do PósCretáceo, relacionado a um período de clima mais seco do que o atual, responsável pela formações de áreas com grande aridez de norte a sul no Brasil.

O equilíbrio geomorforlógico, conforme relatos do Radambrasil (1978) indicam que as vertentes dos relevos mais elevados se apresentam estáveis sob a cobertura vegetal. Os indícios de erosão só foram observados em trechos onde a cobertura vegetal havia sido retirada.

A instalação da floresta mostra que o equilíbrio geomorfológico entre a vegetação, o solo e os relevos dissecados é frágil. Assim a quebra deste equilíbrio pela alteração de qualquer destes elementos poderá acelerar a atuação dos processos erosivos. 


\section{Hidrogeomorfologia}

A forma como o relevo se disposto na TIUEWW e como parte integrante do geossistema, permite a existência de bacias e sub-bacias hidrográficas expressivas como as do Jamari, Jaci Paraná, Candeias Urupá, Jarú, São Miguel, São Francisco, São Domingos, Muqui, Cautário, Cautarinho, Ouro Preto, Jaci-Paraná, e Pacaás Novos.

Desse modo a área de drenagem de uma bacia é a área plana inclusa entre seus divisores topográficos, e segundo Kanindé (2002) dentro da área indígena 2190 rios de $1^{\mathrm{a}}$. ordem, denominados de nascentes, mapeáveis na escala 1:100.000, formando um total de 12 sub-bacias principais, conforme Anexo II.

\section{Conclusão}

As condições geofísicas da TIUEWW e do Parque Nacional de Pacaás Novos, sobreposto à Terra Indígena, tem que ser compreendida como um geossistema, estratégico tanto para Rondônia, quanto para a Amazônia, porém carecem de estudos e análises aprofundadas para se entender sua complexidade ambiental e as especificidades.

Porém as conclusões que chegamos, mesmo que não sem estudos aprofundados, indicam a existência de um ambiente frágil e ao mesmo tempo importante para o desenvolvimento de Rondônia, requerendo um cuidado mais que especial.

Frágil porque as condições que oferecem em termos de solos, vegetação aliado à geologia, hidrogeomorfologia e geomorfologia locais para implantar projetos que envolva agropecuária e mineração, principalmente, trariam prejuízos irreversíveis tanto para o ecossistema quanto para as populações indígenas que dependem desse espaço para tirar seu sustento e conservação de sua identidade cultural.

No momento em que uma das grandes questões da humanidade é colocada numa discussão que exige tomada de decisões urgentes, como é o caso da água, a TIUEWW devido ao grau de conservação e preservação que os povos indígenas com enormes dificuldades exercem o seu papel, constatando-se ser estratégico para o Estado de Rondônia.

Caso houve um processo de antropização incontrolável na TIUEWW, com desmatamento, teríamos como conseqüências o assoreamento das bacias como o do

Ateliê Geográfico Goiânia-GO v. 5,n.1 mar/2011 p.85-102 Página 93


Jamari e Madeira comprometendo a geração de energia elétrica na UHE de Samuel e dos futuros empreendimentos energéticos do Estado, impedindo a navegação dos rios Guaporé e Madeira, ocasionando prejuízos ao desenvolvimento do Estado.

O conhecimento da dinâmica da região e a difusão desse conhecimento, porém não será eficaz, se não for precedido de ações concretas do Estado mediante políticas públicas que considerem as populações existentes, legitimadas por fiscalização e vigilância constantes, evitando desse modo a manipulação e o aliciamento dos materiais naturais por pessoas inescrupulosas junto às nações indígenas.

\section{Referências}

ADAMY, Amílcar. Estudo das formas de relevo. In: Atlas Geoambiental de Rondônia. 2a ed. Porto Velho, SEDAM, 2002.

BATISTA, Israel Xavier. Guimarães, Siane C.P. Uso da terra. In: Atlas Geoambiental de Rondônia. $2^{a}$ ed. Porto Velho, SEDAM, 2002.

$\begin{array}{lrrrr}\text { BRASIL. Recursos } & \begin{array}{c}\text { Naturais e } \\ \text { Informações }\end{array} & \text { sobre } & & \text { Ambientais } \\ \text { Recursos } & \text { Sistematização das } \\ \text { Naturais. }\end{array}$ /home/geociencias/recursosnaturais/sistematizacao/jamari_tabelas.shtm. IBGE, extraído em 25.11.2006.

BRASIL. Departamento Nacional de Produção Mineral. Projeto RADAMBRASIL, Levantamento de Recursos Naturais. Folha SC - 20 Porto Velho, V. 16, Rio de Janeiro, 1978.

CASSETI, Valter. Ambiente e apropriação do relevo. $2^{a}$ ed. São Paulo, Contexto, 1995.

CASSETI, Valter. Compartimentação topográfica. In: Elementos de Geomorfologia. Centro Gráfico da UFG, 2001.

CHRISTOFOLETTI, Antônio. Geomorfologia. 2ª ed. São Paulo, Edgar Blücher, 1980.

Kanindé. Diagnóstico EtnoAmbiental Participativo da Terra Indígena Uru-EuWau-Wau. Porto Velho, Kanindé, 2002.

LEINZ, Viktor Leinz. AMARAL, Sérgio E. do. Geologia Geral. 10ª ed. rev. São Paulo, Nacional, 1987.

MENDES, Ângelo Mansur. A importância do nosso solo. In: Atlas Geoambiental de Rondônia. 2a ed. Porto Velho, SEDAM, 2002. 
MENDES, Ângelo Mansur. Aptidão agrícola. In: Atlas Geoambiental de Rondônia. $2^{\mathrm{a}}$ ed. Porto Velho, SEDAM, 2002.

NASCIMENTO, Eloíza Della Justina. Recursos Naturais da Terra Indígena (Geologia, Geomorfologia, Solos e Recursos Hídricos) In: Diagnóstico EtnoAmbiental Participativo da Terra Indígena Uru-Eu-Wau-Wau. Porto Velho, Kanindé, 2002.

POPP, José H. Geologia geral. $4^{\text {a }}$ ed. São Paulo/Rio de Janeiro, Livros Técnicos e Científicos, 1987.

RAFFESTIN, Claude. Por uma Geografia do Poder. São Paulo, Ática, 1993.

RAIJ, Bernardo van. Avaliação da fertilidade do solo. Piracicaba, Instituto da Potassa e Fosfato e Instituto Internacional da Potassa, 1981.

ROSS, Jurandir Luciano Sanches. Geomorfologia: ambiente e planejamento. $3^{\text {a }}$ ed. São Paulo, Contexto, 1996.

SCANDOLARA, Jaime E. Geologia. In: Atlas Geoambiental de Rondônia. $2^{\mathrm{a}}$ ed. Porto Velho, SEDAM, 2002.

VIEIRA, Lúcio S. VIERA, Maria de Nazareth F. Manual de Morfologia e Classificação de solos. $2^{a}$ ed. São Paulo, Ceres, 1983. 


\section{ANEXO I}

\begin{tabular}{|c|c|c|c|}
\hline \multicolumn{4}{|c|}{ FORMAS DE RELEVO DA TIUEWW } \\
\hline $\begin{array}{c}\text { UNIDADES } \\
\text { GEOMORFOLÓGICAS }\end{array}$ & DESCRIÇÃ̃O & CARACTERÍSTICAS & SOLOS \\
\hline \multirow[t]{3}{*}{ D- Unidades Denudacionais } & $\begin{array}{l}\text { Footslopes } \\
\text { D } 12 \text { - Dissecação Alta }\end{array}$ & $\begin{array}{l}\text { - Unidade observada no sopé de elevações, } \\
\text { comum nas bordas das serras dos Pacaás Novos } \\
\text { e Uopianes. Depósitos gravitacionais associados } \\
\text { a superfícies topograficamente inferiores, em } \\
\text { processo de erosão. Sem processo de } \\
\text { antropização. }\end{array}$ & \multirow{3}{*}{$\begin{array}{l}\text { Latossolos vermelho escuro: Ocorrem em áreas de relevo } \\
\text { plano a relevo ondulado e forte ondulado, com fases de } \\
\text { rochas expostas. } \\
\text { Latossolos Vermelho Amarelo:. Ocorre em áreas de relevo } \\
\text { plano, suavemente ondulado a ondulado, condicionado a } \\
\text { diferentes graus de erosão. } \\
\text { Os Cambissolos. Ocorre em terras firmes com fertilidade } \\
\text { natural baixa. } \\
\text { Neossolos regolíticos com presença de matacões de mais de } \\
1 \text { m de diâmetro. Ocorrem em relevo escarpado sob } \\
\text { vegetação de savana. Diferenciam-se em: AR1 e AR2, } \\
\text { ocorrendo em afloramentos rochosos em relevo plano e } \\
\text { suave ondulado, e forte ondulado e montanhoso. } \\
\text { Neossolos Litólicos são solos pouco desenvolvidos, rasos e } \\
\text { textura arenosa Ocorrem Diferenciam-se em: Rd1; } \\
\text { RD2;RD3 - são litólicos distróficos e, com características } \\
\text { específicas e ocorrem em relevo suave ondulado e ondulado, } \\
\text { forte ondulado e montanhoso, e conforme o caso possui } \\
\text { vegetação de savana/floresta aberta, floresta densa e floresta } \\
\text { aberta. } \\
\text { Neossolos Quartzoarênicos Ocorrem em relevo plano, } \\
\text { suave ondulado e ondulado. } \\
\text { Planossolos Hidromórficos sob relevo plano coberto de } \\
\text { savana. } \\
\text { Em termos de aptidão agrícola, a TIUEWW tem poucas } \\
\text { manchas de solo viáveis a agropecuária e outros manejos de }\end{array}$} \\
\hline & $\begin{array}{l}\text { Superfície de Aplanamento: } \\
\text { D-2210 Nível II - (200/300m de altitude) } \\
\text { Relevo plano e evidências de superfícies } \\
\text { com couraças ferruginosas. } \\
\text { D-2211 Nível II - (200/300m de altitude) } \\
\text { Dissecação baixa e nenhum ou esporádicos } \\
\text { inselbergs e tors. } \\
\text { D-2212 Nível II - (200/300m de altitude) } \\
\text { Dissecação baixa e muitos tors hillocks } \\
\text { residuais. } \\
\text { D-2221 Nível II - (200/300m de altitude) } \\
\text { Dissecação média e nenhum ou esporádicos } \\
\text { inselbergs e tors. }\end{array}$ & $\begin{array}{l}\text { - Constitui unidade que ocorre sobre rochas do } \\
\text { embasamento cristalino. } \\
\text { - As cotas nesta superfície distribuem entre } 200 \\
\text { a } 300 \text { metros, com uma densidade variável de } \\
\text { inselbergs. }\end{array}$ & \\
\hline & $\begin{array}{l}\text { Agrupamentos de morros e colinas } \\
\text { D } 31 \text { - Aberto com colinas/inselbergs } \\
\text { baixos e médios } \\
\text { D } 32 \text { - Denso com colinas/inselbergs } \\
\text { médios e altos. } \\
\text { D } 32 \text { - Área colinosa com alto grau de } \\
\text { dissecação }\end{array}$ & $\begin{array}{l}\text { - Feições geomorfológicas dispersam } \\
\text { regionalmente. Estão subdivididas em } \\
\text { agrupamentos aberto, denso e colinosa. - São } \\
\text { relevos residuais, com diferentes rochas do } \\
\text { embasamento cristalino, com ou sem controle } \\
\text { estrutural nítido. Conhecidas como serras. A } \\
\text { D32 apresenta antropização. }\end{array}$ & \\
\hline
\end{tabular}




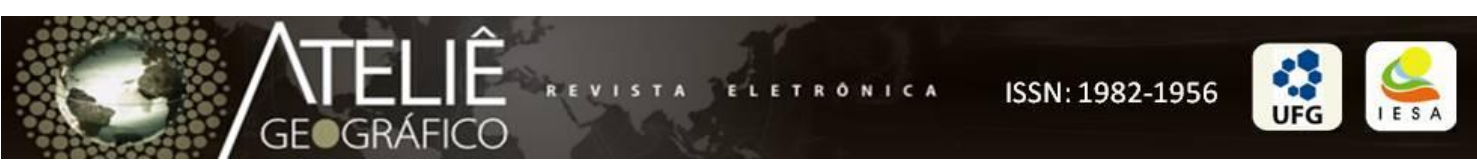

\begin{tabular}{|c|c|c|c|}
\hline $\begin{array}{|lcc|}\text { E } & - & \text { Unidades } \\
\text { Estruturais/Denudacionais }\end{array}$ & \begin{tabular}{|l|} 
Superfícies Tabulares \\
S111 - Em rochas sedimentares com baixa \\
dissecação \\
Cuestas e "hogbacks" \\
S412 - Cuestas com dissecação média e alta
\end{tabular} & $\begin{array}{l}\text { Implantadas em terreno-sedimentares, } \\
\text { subdividas em superfícies tabulares } \\
\text { desenvolvidas em rochas sedimentares, vulcano- } \\
\text { sedimentares e metamórficas, além de cuestas e } \\
\text { hogbacks dispostos em camadas sedimentares. } \\
\text { - Constituem as formas de relevo das serras do } \\
\text { Pacaás Novos e Uopianes, elaboradas sobre } \\
\text { rochas sedimentares com superfícies tabulares, } \\
\text { com fronte abrupta e footslopes, geneticamente } \\
\text { ligada a controle estrutural, fortemente erodidas, } \\
\text { tendo blocos-testemunhos, atingindo até } 1000 \\
\text { metros, com destaque ao Pico do Tracoá, ponto } \\
\text { culminante de Rondônia. }\end{array}$ & maior impacto ambiental. \\
\hline
\end{tabular}

Fontes: Adaptado do Atlas Geoambiental de Rondônia (2002); RADAMBRASIL (1978), Diagnóstico Etnoambiental Participativo da TIUEWW - Kanindé (2002). 
ANEXO II

\begin{tabular}{|c|c|c|c|}
\hline BACIA & $\begin{array}{l}\text { LOCAL DAS } \\
\text { NASCENTES }\end{array}$ & ALTITUDE & OBSERVAÇÃO \\
\hline Cautário & $\begin{array}{c}\text { Serras: Uopianes } \\
\text { Pacaás Novos }\end{array}$ & $\begin{array}{l}650 \mathrm{~m} \\
750 \mathrm{~m}\end{array}$ & $\begin{array}{l}\text { 5.145,741km². Distantes entre si } \\
50 \mathrm{~km} ; 511 \text { rios. Presença de } \\
\text { arenito; Drenagem paralela e } \\
\text { longínea; } \\
\text { diastróficos; grande quantidade } \\
\text { de cachoeiras. }\end{array}$ \\
\hline Jamari & $\begin{array}{l}\text { Serra dos Pacaás } \\
\text { Novos, sopé do } \\
\text { Tracoá }\end{array}$ & $>700 \mathrm{~m}$ & $\begin{array}{l}3.562,766 \mathrm{~km}^{2} \text {. Rochas graníticas, } \\
\text { solo argiloso e substrato rochoso. } \\
\text { Drenagem dendrítica. } 500 \text { rios. } \\
\text { Apresenta corredeiras. }\end{array}$ \\
\hline São Miguel & Serra dos Uoapianes & $600 \mathrm{~m}$ & $\begin{array}{l}2.447,602 \mathrm{~km}^{2} .96 \text { rios. Apresenta } \\
\text { corredeiras. }\end{array}$ \\
\hline Urupá & $\begin{array}{l}\text { Comandante Ari } \\
\text { entre Serras dos } \\
\text { Pacaás Novos e } \\
\text { Mirante }\end{array}$ & & 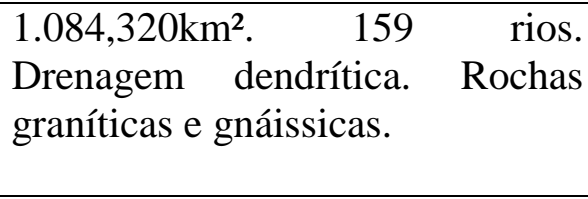 \\
\hline Pacaás Novos & $\begin{array}{l}\text { Serra dos Pacaás } \\
\text { Novos - Pico do } \\
\text { Tracoá }\end{array}$ & $>1000 \mathrm{~m}$ & 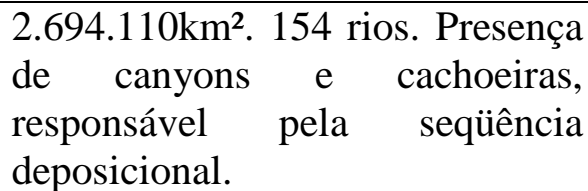 \\
\hline Ouro Preto & $\begin{array}{c}\text { Serra dos Pacaás } \\
\text { Novos }\end{array}$ & $650 \mathrm{~m}$ & $\begin{array}{l}1.120,961 \mathrm{~km}^{2} . \\
\text { encaixado nos sedimentos da } \\
\text { Serra dos Pacaás Novos. } \\
\text { Drenagem regular em relevo } \\
\text { residual tabular e sedimentos } \\
\text { cenozóicos. }\end{array}$ \\
\hline Jaru & Serra do Mirante & $590 \mathrm{~m}$ & $\begin{array}{l}585,017 \mathrm{~km}^{2} .95 \text { rios. } \\
\text { graníticas e gnáissicas. }\end{array}$ \\
\hline Candeias & $\begin{array}{l}\text { Serra Moreira } \\
\text { Cabral }\end{array}$ & $350 \mathrm{~m}$ & $\begin{array}{lccc}476,844 \mathrm{~km}^{2} . & 68 & \text { rios. } & \text { Rochas } \\
\text { graníticas } & \mathrm{e} & \text { colinas } \\
\text { arrendondadas } & & & \\
\end{array}$ \\
\hline Muqui & $\begin{array}{l}\text { Serra Moreira } \\
\text { Cabral }\end{array}$ & $350 \mathrm{~m}$ & $430,506 \mathrm{~km}^{2} .67$ nascentes \\
\hline Jaci-Paraná & $\begin{array}{c}\text { Serra dos Pacaás } \\
\text { Novos }\end{array}$ & & $\begin{array}{l}677,276 \mathrm{~km}^{2} .66 \text { rios. Trechos } \\
\text { encachoeirados. } \\
\text { tabulares. Drenagem retangular } \\
\text { devido às linhas de fratura da } \\
\text { Serra dos Pacaás Novos. Trechos } \\
\text { de relevo plano a suavemente } \\
\text { ondulado, apresenta meandros } \\
\text { irregulares. }\end{array}$ \\
\hline Cautarinho & Serra dos Uopianes & $250 \mathrm{~m}$ & $350,524 \mathrm{~km}^{2} .37$ rios. \\
\hline $\begin{array}{c}\text { São } \\
\text { Domingos }\end{array}$ & Serra dos Uopianes & $250 \mathrm{~m}$ & $122,470 \mathrm{~km}^{2} .11$ rios \\
\hline
\end{tabular}

Fonte: Diagnóstico Etnoambiental Participativo da da TIUEWW - Kanindé (2002). 


\section{Características das Classes de Potencialidades Natural das Terras}

\begin{tabular}{|c|c|c|c|c|c|c|c|}
\hline \multicolumn{6}{|c|}{ POTENCIALIDADE NATURAL AGRÍCOLA DAS TERRAS } & \multicolumn{2}{|c|}{$\begin{array}{c}\text { INFORMAÇÕES } \\
\text { COMPLEMENTARES }\end{array}$} \\
\hline \multicolumn{2}{|c|}{ Classe } & 巳ֶ, & $\begin{array}{c}\text { Solo/Tipo } \\
\text { de Terreno }\end{array}$ & Relevo & $\begin{array}{l}\text { Principais } \\
\text { Limitações }\end{array}$ & $\begin{array}{l}\text { Suscetibilidade } \\
\text { a Erosão }\end{array}$ & $\begin{array}{c}\text { Classes de Solos } \\
\text { Dominantes }\end{array}$ \\
\hline \multirow{2}{*}{$\mathbf{A}$} & 1 & \multirow{2}{*}{ คี } & $\begin{array}{l}\text { Fertilidade natural alta } \\
\text { Bem a moderadamente drenado } \\
\text { Profundo } \\
\text { Boa capacidade de armazenamento de água. }\end{array}$ & $\begin{array}{l}\text { Plano e suave } \\
\text { ondulado }\end{array}$ & & Fraca a moderada & $\begin{array}{l}\text { Podzólico } \\
\text { Vermelho-Amarelo }\end{array}$ \\
\hline & 2 & & $\begin{array}{l}\text { Fertilidade natural baixa } \\
\text { Bem drenado } \\
\text { Muito profundo } \\
\text { Boa capacidade de armazenamento de água }\end{array}$ & $\begin{array}{l}\text { Plano e suave } \\
\text { ondulado }\end{array}$ & $\begin{array}{l}\text { Fertilidade natural } \\
\text { baixa, } \\
\text { Elevado teor de } \\
\text { alumínio trocável }\end{array}$ & Fraca & $\begin{array}{l}\text { Latossolo } \\
\text { Vermelho-Amarelo }\end{array}$ \\
\hline \multirow[b]{2}{*}{ B } & 1 & \multirow{2}{*}{ 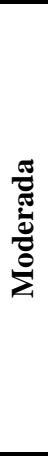 } & $\begin{array}{l}\text { Fertilidade natural média e baixa } \\
\text { Bem a moderadamente drenado } \\
\text { Muito profundo e profundo } \\
\text { Boa capacidade de armazenamento de água }\end{array}$ & $\begin{array}{lr}\text { Plano, } & \text { suave } \\
\text { ondulado } & \mathrm{e} \\
\text { ondulado. } & \end{array}$ & $\begin{array}{l}\text { Fertilidade natural } \\
\text { média e baixa } \\
\text { Elevados teores de } \\
\text { alumínio trocável, } \\
\text { Ligeira restrição por } \\
\text { relevo }\end{array}$ & Fraca a moderada & $\begin{array}{l}\text { Terra Roxa } \\
\text { Estruturada e } \\
\text { Podzólico } \\
\text { Vermelho-Amarelo }\end{array}$ \\
\hline & 2 & & $\begin{array}{l}\text { Fertilidade natural média e baixa } \\
\text { Bem e moderadamente drenado } \\
\text { Muito profundo e profundo } \\
\text { Boa capacidade de armazenamento de água }\end{array}$ & $\begin{array}{lr}\text { Plano, } & \text { suave } \\
\text { ondulado } & \mathrm{e} \\
\text { ondulado. } & \end{array}$ & $\begin{array}{l}\text { Fertilidade natural } \\
\text { média e baixa } \\
\text { Elevados teores de } \\
\text { alumínio trocável, } \\
\text { Presença de plintita } \\
\text { e cascalho e } \\
\text { Moderada restrição } \\
\text { por relevo }\end{array}$ & Fraca e moderada & $\begin{array}{l}\text { Latossolos Amarelo } \\
\text { e Vermelho- } \\
\text { Amarelo e } \\
\text { Podzólico } \\
\text { Vermelho-Amarelo }\end{array}$ \\
\hline \multirow{2}{*}{$\mathbf{C}$} & 1 & \multirow{2}{*}{ 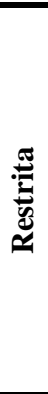 } & $\begin{array}{l}\text { Fertilidade natural baixa e média } \\
\text { Bem drenado } \\
\text { Profundo } \\
\text { Moderada a boa capacidade de armazenamento de } \\
\text { água }\end{array}$ & $\begin{array}{l}\text { Suave ondulado e } \\
\text { ondulado }\end{array}$ & $\begin{array}{l}\text { Fertilidade natural } \\
\text { média e baixa, } \\
\text { Elevados teores de } \\
\text { alumínio trocável e } \\
\text { Moderada restrição } \\
\text { por relevo }\end{array}$ & Moderada & $\begin{array}{l}\text { Podzólico } \\
\text { Vermelho- Amarelo }\end{array}$ \\
\hline & 2 & & $\begin{array}{l}\text { Fertilidade natural baixa } \\
\text { Imperfeita a moderadamente drenado } \\
\text { Muito profundo e profundo } \\
\text { Muito boa e boa capacidade de armazenamento de } \\
\text { água }\end{array}$ & $\begin{array}{l}\text { Plano e suave } \\
\text { ondulado }\end{array}$ & $\begin{array}{l}\text { Fertilidade natural } \\
\text { baixa Elevados } \\
\text { teores de alumínio } \\
\text { trocável } \\
\text { Presença de plintita } \\
\text { eExcesso de água }\end{array}$ & Fraca a moderada & $\begin{array}{l}\text { Plintossolo e } \\
\text { Gleissolo }\end{array}$ \\
\hline \multirow[t]{2}{*}{$\mathbf{D}$} & 1 & \multirow[t]{2}{*}{ 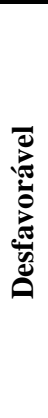 } & $\begin{array}{l}\text { Fertilidade natural baixa a alta } \\
\text { Moderada a imperfeitamente drenado } \\
\text { Muito profundo a raso } \\
\text { Alta a baixa capacidade de armazenamento de } \\
\text { água }\end{array}$ & Plano a montanhoso & $\begin{array}{l}\text { Fertilidade natural } \\
\text { baixa e média, } \\
\text { Elevados teores de } \\
\text { alimínio, Elevada } \\
\text { restrição por relevo, } \\
\text { Presenças de } \\
\text { petroplintita e de } \\
\text { cascalho, } \\
\text { Pouca profundidade } \\
\text { do solo e Excesso } \\
\text { de agua }\end{array}$ & Muito Forte & $\begin{array}{l}\text { Cambissolo, Podzol } \\
\text { Hidromórfico, } \\
\text { Podzólico } \\
\text { Vermelho-Amarelo, } \\
\text { Terra Rocha } \\
\text { Estruturada e Solo } \\
\text { Litólico }\end{array}$ \\
\hline & 2 & & Rocha exposta & $\begin{array}{ll}\begin{array}{l}\text { Plano } \\
\text { ondulado }\end{array} & \text { forte } \\
\end{array}$ & Rocha exposta & & $\begin{array}{l}\text { Afloramentos de } \\
\text { Rochas }\end{array}$ \\
\hline
\end{tabular}




\section{CONCEITOS EMPREGADOS NA ELABORAÇAO DA LEGENDA}

\section{FERTILIDADE NATURAL}

Compreende a análise dos atributos químicos do solo sob a ótica das potencialidades e restrições que possam interferir favorecendo ou restringindo o desenvolvimento das plantas.

Alta - Saturação por bases maior que 50\% (solos eutróficos), resultando em alta reserva de nutrientes para as plantas.

Média - Saturação por bases e por alumínio trocável menor que 50\% (solos distróficos), resultando em média reserva de nutrientes para as plantas.

Baixa - Saturação por bases menor que 50\% e por alumínio trocável maior que 50\% (solos álicos), resultando em baixa reserva de nutrientes para as plantas.

\section{CARACTERÍSTICAS FÍSICAS}

Compreende a análise dos atributos físicos dos solos que possam interferir no pleno desenvolvimento das plantas como, por exemplo, textura, agregação, profundidade, plintita, petroplintita, horizontes adensados ou cimentados, pedregosidade entre outros.

Favorável - Conjunto de atributos que promovam boa capacidade de armazenamento de água e boa aeração do solo, proporcionando boa utilização ao uso agrícola.

Regular - Conjunto de atributos que promovam moderada capacidade de armazenamento de água e na aeração do solo, proporcionando moderada utilização ao uso agrícola.

Desfavorável - Conjunto de atributos que interfiram significativamente na capacidade de armazenamento de água e na aeração do solo, proporcionando forte restrição ao uso agrícola.

\section{SUSCETIBILIDADE A EROSÃO}

A suscetibilidade a erosão foi avaliada a partir da interação entre as características físicas e químicas do solo com a topografia.

Fraca - Compreende terras quando submetidas ao uso agrícola os processos de degradação são facilmente controlável com práticas simples de manejo.

Moderada - Compreende terras quando submetidas ao uso agrícola os processos de degradação exigem práticas intensivas de conservação.

Forte - Compreende terras quando submetidas ao uso agrícola os processos de degradação exigem práticas muito intensivas de controle ou até mesmo são inaptas ao uso.

\section{RELEVO}

- Plano - Superfície com declives menores que 3\%.

- Suave ondulado - Superfície com declives entre 3 e $8 \%$.

- Ondulado - Superfície com declives entre 8 e $20 \%$.

- Forte ondulado - Superfície com declives entre 20 e $45 \%$.

- Montanhoso - Superfície com declives entre 45 e $75 \%$. 
QUANTIFICAÇÃO DAS CLASSES DE POTENCIALIDADES NATURAL AGRÍCOLA DAS TERRAS

\begin{tabular}{|c|c|c|c|c|c|c|c|}
\hline \multicolumn{3}{|c|}{$\begin{array}{c}\text { Classes de Potencialidade Natural } \\
\text { Agrícola das Terras }\end{array}$} & Área $\mathrm{Km}^{2}$ & $\begin{array}{l}\% \text { do } \\
\text { Total }\end{array}$ & Município* & Área $\mathrm{Km}^{2}$ & $\begin{array}{c}\text { \% do Total no } \\
\text { Município } \\
\text { dentro da }\end{array}$ \\
\hline \multirow{13}{*}{ Boa } & \multirow{13}{*}{ A } & \multirow{3}{*}{1} & \multirow{3}{*}{$2.532,00$} & \multirow{3}{*}{8,71} & Ariquemes & 979,18 & 24,10 \\
\hline & & & & & Cacaulândia & 839,82 & 42,09 \\
\hline & & & & & Governador Jorge Teixeira & 713,00 & 18,97 \\
\hline & & \multirow{10}{*}{2} & \multirow{10}{*}{$8.623,19$} & \multirow{10}{*}{29,67} & Porto Velho & $1.948,06$ & 46,50 \\
\hline & & & & & Candeias do Jamari & 533,34 & 12,45 \\
\hline & & & & & Jamari & 548,75 & 31,20 \\
\hline & & & & & Alto Paraíso & $2.312,63$ & 87,11 \\
\hline & & & & & Rio Crespo & $1.227,12$ & 91,84 \\
\hline & & & & & Cujubim & 256,86 & 99,86 \\
\hline & & & & & Ariquemes & $1.565,00$ & 38,52 \\
\hline & & & & & Buritis & 151,91 & 11,58 \\
\hline & & & & & Monte Negro & 26,14 & 1,86 \\
\hline & & & & & Cacaulândia & 53,38 & 2,68 \\
\hline \multirow{15}{*}{ Moderada } & \multirow{15}{*}{ B } & \multirow{8}{*}{1} & \multirow{8}{*}{$3.844,63$} & \multirow{8}{*}{13,23} & Rio Crespo & 68,29 & 5,11 \\
\hline & & & & & Candeias do Jamari & 3,97 & 0,09 \\
\hline & & & & & Ariquemes & 124,48 & 3,06 \\
\hline & & & & & Buritis & 51,55 & 3,93 \\
\hline & & & & & Monte Negro & 695,44 & 49,52 \\
\hline & & & & & Campo Novo de Rondônia & $1.042,29$ & 50,77 \\
\hline & & & & & Cacaulândia & 279,75 & 14,02 \\
\hline & & & & & Governador Jorge Teixeira & $1.578,86$ & 41,98 \\
\hline & & \multirow{7}{*}{2} & \multirow{7}{*}{$7.511,95$} & \multirow{7}{*}{25,84} & Porto Velho & $1.479,73$ & 35,32 \\
\hline & & & & & Candeias do Jamari & $3.348,17$ & 78,17 \\
\hline & & & & & Jamari & $1.036,29$ & 58,91 \\
\hline & & & & & Alto Paraíso & 162,28 & 6,11 \\
\hline & & & & & Buritis & 709,55 & 54,06 \\
\hline & & & & & Campo Novo de Rondônia & 470,94 & 22,94 \\
\hline & & & & & Governador Jorge Teixeira & 304,99 & 8,11 \\
\hline \multirow{9}{*}{ Restrita } & \multirow{9}{*}{$\mathrm{C}$} & & & & Porto Velho & 396,47 & 9,46 \\
\hline & & & & & Alto Paraíso & 69,74 & 2,63 \\
\hline & & & & & Ariquemes & 758,93 & 18,68 \\
\hline & & 1 & $1.845,62$ & 6,35 & Buritis & 176,53 & 13,45 \\
\hline & & & & & Monte Negro & 271,52 & 19,34 \\
\hline & & & & & Campo Novo de Rondônia & 104,60 & 5,10 \\
\hline & & & & & Governador Jorge Teixeira & 67,83 & 1,80 \\
\hline & & 2 & 7418 & 026 & Porto Velho & 72,29 & 1,73 \\
\hline & & 2 & 14,18 & 0,20 & Candeias do Jamari & 1,89 & 0,04 \\
\hline & & & & & Porto Velho & 232,18 & 5,54 \\
\hline & & & & & Candeias do Jamari & 40,62 & 0,95 \\
\hline & & & & & Alto Paraíso & 96,13 & 3,62 \\
\hline & & & & & Rio Crespo & 40,78 & 3,05 \\
\hline & & & & & Ariquemes & 631,61 & 15,55 \\
\hline & & 1 & $3.998,77$ & 13,76 & Buritis & 222,77 & 16,98 \\
\hline & & & & & Monte Negro & 411,07 & 29,28 \\
\hline Desfavorável & $\mathrm{D}$ & & & & Campo Novo de Rondônia & 422,28 & 20,57 \\
\hline & & & & & Jamari & 23,04 & 1,31 \\
\hline & & & & & Cacaulândia & 822,05 & 41,21 \\
\hline & & & & & Governador Jorge Teixeira & $1.056,24$ & 28,09 \\
\hline & & & & & Campo Novo de Rondônia & 12,69 & 0,62 \\
\hline & & 2 & 52.47 & 018 & Candeias do Jamari & 0,01 & 0,001 \\
\hline & & 2 & 52,41 & 0,18 & Jamari & 0,10 & 0,01 \\
\hline & & & & & Governador Jorge Teixeira & 39,67 & 1,05 \\
\hline
\end{tabular}




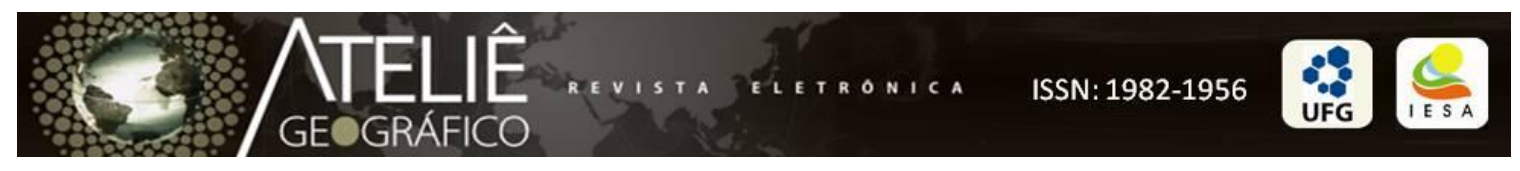

Recebido para publicação em outubro de 2010 Aprovado para publicação em dezembro de 2010 